Fotografia: Sílvia Aguião. Manifestação pública do movimento LGBT em frente à Câmara dos Vereadores no Rio de Janeiro (RJ).

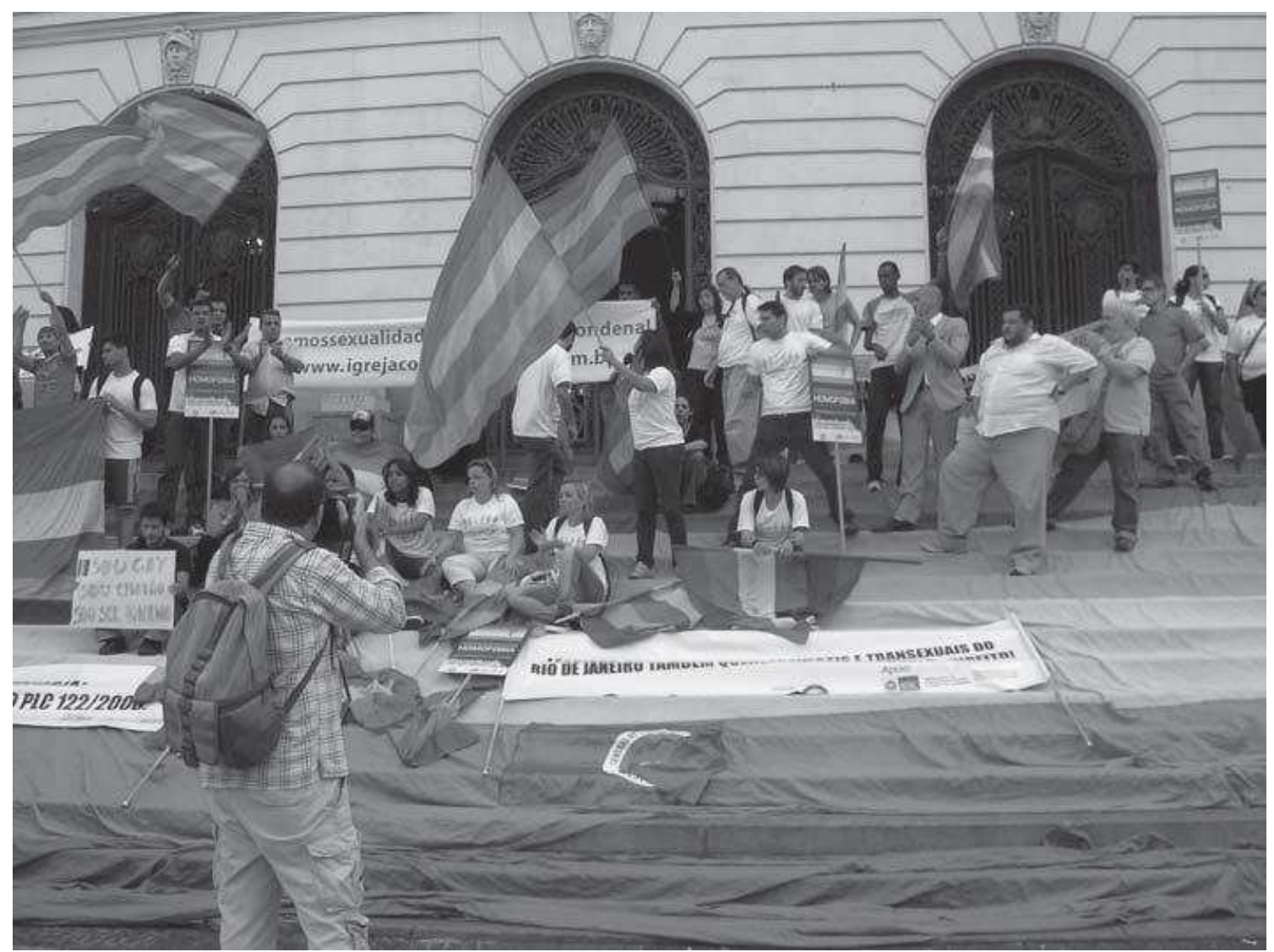




\section{Diferencias y identidades sexuales: lecturas críticas desde la economía y la ciencia política*}

Mónica Solange De Martino Bermúdez**

Resumen: Exponemos aquí reflexiones derivadas del proyecto de investigación Ser Hombres, Ser Padres en Contextos de Pobreza'. Intentamos, a modo de ensayo más que de artículo, exponer algunas cuestiones teóricas que hacen a las categorías minoría e identidad sexual. Intentamos desentrañar qué está en juego más allá del respeto a la diversidad sexual. Nuestra hipótesis es que las minorías sexuales poseen cierta tendencia a la hipercorrección cívica, respondiendo a los sueños más pesados de la racionalidad occidental. Dicha tendencia reduciría su potencial político/emancipatorio. Del mismo modo creemos que desafía teórica y éticamente al Trabajo Social, en la medida que la simple adhesión a la diversidad invisibiliza la relación entre aquellas y ciertas características de la cultura de este capitalismo tardío.

Palabras clave: Minorías sexuales; economía política; ciencia política.

Resumo: Relatamos aqui reflexões derivadas do projeto de pesquisa intitulado Ser Homens, Ser Pais em Contextos de Pobreza. ${ }^{2}$ Tentamos desvendar o que está em jogo além do respeito à diversidade sexual. Nossa hipótese é que as minorias sexuais têm uma tendência à hipercorreção cívica, respondendo aos sonhos mais pesados da racionalidade ocidental. Essa tendência reduziria o seu potencial político/emancipatório. Da mesma forma, acreditamos que desafia teórica e eticamente ao Trabalho Social, na medida em que a adesão irrefletida ao respeito à diversidade não faz visível a relação daquela com certas características da cultura do capitalismo tardio.

Palavras-chaves: Minorias sexuais; economia política; ciência política.

\footnotetext{
* Este artículo profundiza algunos aspectos de la ponencia presentada en la VIII Conferencia Iberoamericana sobre Familias y II Conferencia Nacional sobre Familias. Cuestión Social, Derechos Humanos y Políticas Familiares en Iberoamérica: Avances, Desafíos y Perspectivas. Ambas realizadas del 25 al 27 de noviembre de 2009. Buenos Aires, Argentina.

** Asistente Social, Grado en Sociología. Doctora en Ciencias Sociales por la Universidad Estatal de Campinas Brasil. Profesora Titular en Régimen de Dedicación Total del Departamento de Trabajo Social de la Facultad de Ciencias Sociales - Universidad de la República, Montevideo, Uruguay. E-mail: monicad@fcs.edu.uy

${ }^{1}$ Proyecto realizado en base a las horas del Régimen de Dedicación Total, parcialmente financiadas por la Comisión Sectorial de Investigación Científica de la Universidad de la República Uruguay.

${ }^{2}$ Projeto realizado com base nas horas de regime de DedicaçãoTotal, parcialmente financiado pela Comissão Setorial de Investigação Científica da Universidade da República Oriental do Uruguai.

${ }^{3}$ Project carried out based on the hours of Full Time Dedication Scheme, partially financed by the Sectoral Commission for Scientific Research from the University of the Republic of Uruguay.
} 


\section{ReVistg all pgutg}

\} DIFERENCIAS Y IDENTIDADES SEXUALES: LECTURAS CRÍTICAS - BERMÚDEZ, M. S. M. \}

\section{Introducción}

En el presente artículo, que optamos por presentar a modo de ensayo, intentamos realizar una serie de puntualizaciones respecto a aquellas minorías vinculadas a su condición y opción sexual - hombre/mujer homosexuales, transexuales, travestis, bisexuales, etc. - hoy denominadas y reconocidas como Población LGTB. Nuestra hipótesis es que tales minorías - y los movimientos político-culturales que las representan - poseen cierta tendencia a la hipercorrección cívica - es decir, formar pareja estable con sustento legal, tener hijos etc. - en base a los sueños tal vez más pesados de la racionalidad occidental. Más concretamente, en base a las expresiones más potentes de dicha racionalidad: la medicina y el derecho.

El artículo no trata sobre los derechos, dolorosa y combativamente conquistados por la población LGTB - derechos que reconocemos y respetamos. Más bien intenta hablar sobre sus identidades como asunto, preocupación y conflicto, desplazados en la conformación de arreglos afectivos-sexuales, por ejemplo, que podrían ser paradójicamente llamados "tradicionales" ya que no logran separarse de lo prescripto/normativo para cualquier pareja heterosexual. El ensayo trata, con sumo respeto, de indagar si la conformación de "minorías" no se asociaría a una anécdota fundacional que subraya una identidad y una cultura determinada, basada en ciertos mitos antropológicos como la grandeza de la soledad, el desamparo de la manada y la ternura de una comunidad en un ambiente hostil.

La argumentación articula pares conceptuales: minoría/comunidad, estigma/ carencia, familia/manada, políticas de reconocimiento/políticas económicas. Sostenemos, como aproximación, y reconociendo las luchas y logros de tales minorías, que en los sueños realizados (matrimonio igualitario, derecho a la reproducción, herencia de los bienes de sus parejas, etc.) se desliza cierta ingenuidad: construir un puente entre sociedad y comunidad, a partir de la construcción de arreglos afectivos-sexuales que funcionan como síntesis entre la familia y la minoría como manada, entre la comunidad estigmatizada y una sociedad hipócrita, entre libre elección y corporativismo, entre identidad e no diferenciación. Puente y síntesis que no logran superar la mera reproducción de la sociedad que los engendra: sociedades injustas y desiguales en tiempos del capitalismo tardío.

\section{Minorías sexuales y la Sagrada Familia.}

Parecería ser que la población homosexual, transexual o bisexual ya no quiere sólo vivir en pareja. Quiere "casarse", quiere una unión sancionada por el Estado, aceptada por su familia de origen y socialmente legitimada. Incluso tal vez respetarán la tradición patriarcal de la división sexual del trabajo. Su propia diversidad o diferencia, parece ser anulada por una postura hipercorrecta que busca redimir a la homosexualidad, negando estereotipos estigmatizantes históricamente imputados a ella. Ya no es la homosexualidad asociada a lo promiscuo, al dandy, al travesti, a la loca o rara. Estas parejas, siempre injustamente bajo sospecha, ya no tiene grandes problemas con la autoridad. Serán algo bueno, correcto, purificado en el mito del amor romántico, pacífico y espiritual, luego de haber sido tan mal asociadas a tanto cuerpo y tanto pecado. Necesitan una gran matriz familiar, en lo posible blanca y tolerante, que las acepte, la reabsorba y ipor qué no?, las quiera. 


\section{hevista all pautg}

\} DIFERENCIAS Y IDENTIDADES SEXUALES: LECTURAS CRÍTICAS - BERMÚDEZ, M. S. M. \}

Pero bien, avancemos en nuestras reflexiones. En primer lugar cabe explicitar qué entendemos por minoría, categoría que funciona como hilo conductor de nuestro trabajo. Entendemos por minoría a todo grupo social con un comportamiento de tipo endoreflexivo - reivindicativo, justificado por una marca o estigma (GOFFMAN, 1999), que funciona como carácter recesivo frente a otro dominante al que se opone. Otro concepto como el de carencia, aparece como una palabra clave para entender la arquitectura y funcionamiento de la noción de minoría. Toda minoría se quiere organizada alrededor no de una carencia - aquello que la niega- sino de una identidad, en la medida que identidad es la negación de la carencia. Una noción que transforma la falta en una positividad, Ilena de discurso, de teoría y de autoconocimiento. Casi como una operación mágica, se pone plenitud allí donde las mayorías indicaban la existencia de un vacío. Ya no una carencia, sino una identidad. Ya no la aparente corrección cívica, eufemística y reverencial de "minorías sexuales" sino la corrección política de gays, lesbianas, transexuales y travestis.

La constitución de una minoría podría ser pensada de acuerdo a un movimiento en dos tiempos a partir del tema clásico del "estigma" de Goffman (1999). Primer paso: el estigma se transforma en identidad. Segundo paso: la identidad se transforma en pedigree.

Vale la pena detenerse en el primer paso: su generalidad es básica para entender la historia política del capitalismo moderno, pero también trivial para comprender la historia posmoderna de las minorías. Podría decirse que la modernidad civil comienza cuando el estigma o la marca, empiezan a ser tratados como identidad. Comenzaría así la era de la creación de subjetividades y de la gran utopía de lo político: el nacimiento del Estado político moderno y su contracara, la sociedad civil. Su discurso-emblema es el psicoanálisis que plantea el problema de la hermenéutica del yo como nuevo procedimiento y nuevo discurso de gobierno o poder político (FOUCAULT, 2001). Hay que hacer hablar, dejar hablar al otro; transformar el rasgo patológico (marca, trastorno o defecto, definido de manera arbitraria en un lógica binaria de normal/patológico con la que obviamente no estamos de acuerdo) en rasgo identitario (síntoma, interpretabilidad). La gran tarea del Estado político moderno es interpretar e interpelar, producir identidad y crear sujetos.

Con respecto al segundo paso: la identidad se transforma en pedigree. Tal vez sea pueril, pero sólo dado ese paso la minoría se fabrica a la manera de una corporación, como un pequeño "paraíso" comunitario.

Si retomamos nuestra hipótesis, la parte más previsible de la hipercorrección cívica de las minorías sexuales, a saber: casarse legalmente y tener hijos, está asistida, como ya fue dicho en la Introducción, por los sueños más pesados de la racionalidad de occidente y de unas de las formas más fuertes de esa racionalidad: la médica y la jurídica.

Creemos que algo grave ocurre en tiempos de un capitalismo mundializado y obsceno. Antes comprendíamos el mundo: teníamos hipótesis de intelección y robustos sistemas teóricos. La gran pregunta filosófica de Occidente era ¿Por qué?, hecha por la curiosidad sana de un Espíritu proyectándose en progreso.

Ahora acumulamos conocimiento en las formas más sofisticadas del capital tecnológico: manipulamos todo y podemos fabricar eventualmente todo. Llegamos 


\section{ReVistg all pgutg}

\} DIFERENCIAS Y IDENTIDADES SEXUALES: LECTURAS CRÍTICAS - BERMÚDEZ, M. S. M. \}

al Saber Absoluto. La pregunta ya no es ¿Por Qué?, sino ¿Por qué no? Podemos manipular huevos, matrices y embriones: ¿por qué no embarazar a un hombre? ¿Por qué no embarazar a una mujer sin que intervenga el varón? ¿Por qué no hacerlo por una buena causa: el respeto a las minorías? La variada tecnología de la asistencia a la fertilidad apoya a las minorías sexuales produciendo el deseo en realidad. Las Ilamadas manipulaciones homoparentales refuerzan lo endogámico: "Es posible tener hijos sin relación sexual con alguien del otro sexo." Hoy esto es posible, pero no es esto lo que discutimos. Lo que tratamos de discernir es el ideario político actual de las minorías sexuales y cierta funcionalidad no visible con algunas características del capitalismo tardío.

La anécdota fundacional de estos arreglos afectivo-sexuales es previsible. Habla de identidad como asunto, preocupación y conflicto; una identidad que históricamente ha sido socialmente rechazada y que en tanto conflicto individuo/comunidad/sociedad es desplazado, volcado masivamente no sobre el cuerpo y las opciones sexuales sobre qué hacer con ese cuerpo. Ese conflicto es volcado sobre el campo de lo político: los derechos de tales minorías. Si observamos las noticias relativas a artistas famosos que han recurrido a mecanismos diversos de fertilización asistida, parecería que conformar una familia homosexual habla de celebrar una identidad y una cultura; también vagamente de ciertos mitos antropológicos, como la grandeza de la soledad, el desamparo de la manada y de la ternura de su comunión en un ambiente hostil. Habla de un fuerte sentimiento de pertenencia a y de pedigree en la familia/comunidad creada.

\section{Minorías sexuales, reproducción y la economía política: una relación invisible para la profesión}

¿Es sólo el juego imaginario de estos grupos familiares - el orgullo, la identidad, la cultura o el sentido de la pertenencia - lo que explica o justifica la existencia de estos arreglos afectivo-sexuales?

Cuando una sociedad ya no ofrece nada por qué pelear colectivamente, nada que convoque a la lucha por todos y cada uno de sus integrantes, cuando no ofrece nada que defender, se puede crear - ¿Por qué no? - lo que va a defender y defender lo que va a crear. Aparecen las minorías, la singularidad. Parecería que hay una energía civil que no sabe en qué gastarse. Especialmente cuando observamos esas luchas en una clase educada, con un discreto deseo de lucha y de resistencia, sin que haya algo más abarcativo por lo que valga la pena luchar o contra qué resistir. Si hablamos de minorías sexuales, ni su creación ni la defensa de su creación le pertenecen a la historia de la liberación o la resistencia, a la historia de la lucha de los oprimidos. Le pertenecen, tristemente, a la historia del aburrimiento civil en el mundo desarrollado. Hablemos claro, nos referimos a minorías sexuales, atravesadas por su pertenencia a ciertas clases sociales y no a los movimientos claramente políticos que han surgido en torno a ellas.

Corrijamos: aburrimiento civil de cierto momento histórico. ¿Cuándo si no en tiempo del capitalismo tardío, del consumo por encima de la producción, del liberalismo político, podría haber ocurrido? Aburrimiento civil de una clase social: ¿en qué sectores sociales sino en los acomodados del mundo desarrollado podrían 


\section{hevista all pautg}

\} DIFERENCIAS Y IDENTIDADES SEXUALES: LECTURAS CRÍTICAS - BERMÚDEZ, M. S. M. \}

haber aparecido la defensa de tales derechos? ¿Lesbianas o gays pobres pueden acceder a sofisticadas técnicas de fertilización asistida y poseer un nivel cultural que les permita elaborar un discurso para fundamentar su decisión? ¿Trasvestis de los suburbios, transexuales de lumpen proletariado son la cara visible de tales minorías e incluso de las organizaciones que los representan en la lucha por el matrimonio igualitario? Es también cierta cultura y educación: ¿cómo podría haberse dado este proceso, sino a través de la ideología, la doctrina y, en suma, del espíritu de la nueva izquierda, los multiculturalismos, el posestructuralismo?

También esta situación habla de cierta geografía política: ¿dónde se hubiera situado, si no, en el mundo reformista-protestante, con su psicología de colono, con su dinámica comunitaria incesante entre la paranoia policíaca y la tolerancia horizontal indiferenciada? Estamos hablando de los Estados Unidos más precisamente.

Esta cultura, anclada en una economía política específica, cumple con la solicitud de mantener todas las opciones abiertas, quizás menos por una verdadera vocación democrática y tolerante, que por no tener la fuerza de mantener algunas opciones que le gustaría tener cerradas - no es esta nuestra posición, es decir, no estamos a favor de la obturación de opciones. Opciones abiertas, es la expresión políticamente correcta, del ¿por qué no? posthegeliano. En una democracia que se alimenta no tanto de los grandes valores liberales (permisividad, tolerancia, respeto a la diversidad y a la diferencia) cuanto de sus formas convencionales, de sus rituales y ceremonias, no es raro que el estilo democrático, se tramite coercitivamente. En este caso, a partir de lo creado, de arreglos afectivo-sexuales/comunidades producidas intencionalmente.

\section{Problematizando la noción de pedigree: respuesta profunda y dolida con escasa proyección política}

En los años ochenta se simpatizaba fácilmente con el concepto de minoría, como una especie de discreta reserva de utopías. Al ponerse en escena como una lucha en condiciones desventajosas contra un gran poder normalizador y estigmatizante, la minoría mostraba el camino de su indocilidad. Era posible reconocer en las luchas por los derechos civiles de las minorías a esa nueva izquierda que muchos esperaban: utópica, impura, despareja, que tenía como inspiración fuertes críticas y luchas sostenidas en una vasta teoricidad: feminismo, gender studies, men's studies, gays and lesbians studies, etc.

La situación parecería estar más bien fundada en un terreno híbrido de culturas rituales, luteranas y pragmáticas, profundamente disciplinarias y policíacas, con dosis de liberalismo político, todo edificado sobre suelos de liberalismo económico de circulación y consumo. La idea de minoría no pertenece a la tradición críticodialéctica. No proviene de una cultura institucionalista de la gobernabilidad. Minoría no proviene de la carencia latina, sino del estigma protestante.

En párrafos anteriores definimos que la comunidad minoritaria decanta en el recorrido que lleva del estigma (vacío, carencia) a identidad (teoría, discursividad, diferencia) y de ahí a pedigree (orgullo y pertenencia). Ahora queremos elaborar nuevamente esa afirmación. 


\section{ReVistg all pgutg}

\} DIFERENCIAS Y IDENTIDADES SEXUALES: LECTURAS CRÍTICAS - BERMÚDEZ, M. S. M. \}

Estigma no es igual a carencia: estigma es cicatriz, herida, marca, carta de identificación. Carencia, en cambio, es un tema jurídico-político, pertenece al escenario de los derechos civiles y remite a dispositivos de construcción de sujetos. Carencia-necesidad-derecho: aquello que Yo tengo o soy, aquello que le falta al otro (para ser Yo), aquello que el otro tiene derecho a ser o a tener (para ser Yo).

Estigma, como dispositivo militar en lenguaje foucaultiano, vive en los espacios de interacción y pragmáticos de la cultura protestante, en ambientes hechos de reglas y normas reguladoras del comportamiento comunitario y en una cultura que funciona a partir de la separación reguladora entre sano y enfermo, normal y anormal. Estigma sirve como elemento táctico y estratégico para tales segmentaciones, para clasificar y descartar. Basta pensar en la obra "Los Anormales" de M. Foucault. Pero más que remitirnos a este autor, consideramos que el tratamiento del tema que hace Goffman (1999) es interesante por lo sintomático.

Carencia es estrictamente al revés: prospera en lo público-político, es decir, en el gran espacio de la Ley y la Prohibición. Estigma vigila, regula, hace enmudecer, excluye. Carencia, en cambio, gobierna, administra, anexa, hace hablar. Nos habla de sociedad, de grupos en situación de carencia, de movimientos de resistencia, de posturas gubernamentales con relación a ella. Estigma nos hace pensar en instituciones, ciencias y disciplinas que cercan al portador de esa marca.

Para las culturas institucionales, identidad parece indisociable de soberanía. Identidad contiene una operación de separación, de discriminación simbólica, dialéctica, con respecto al que me somete, al discurso del amo. Conocerme es emanciparme y hacerme soberano. En cambio, el pedigree, el orgullo de la marca alrededor de la cual se congrega y cohesiona la minoría, no proviene de teorizaciones o elaboraciones discursivas de la diferencia como identidad. La dialéctica estigma-pedigree es, en última instancia, acrítica y asimbólica: pedigree es una réplica hiperrealista, una respuesta contundente al daño real del estigma, una reacción, una respuesta defensiva ante una agresión exterior. Quizás la contundencia de la respuesta, es decir, el construir minorías, se relacione con el origen de todo estigma. El estigma proviene de una forma de poder anterior y más rudimentario que la política: el poder panóptico o un poder policíaco que toma, captura, controla; que me separa, me marca no en lo simbólico sino en lo real, en el cuerpo. (FOUCAULT, 1977b; DONZELOT, 1986) El discurso etológico ${ }^{4}$, es el modelo del saber-control panóptico sobre el otro, especialmente cuando ese otro es diferente.

Ante ese discurso etológico, funcional al poder panóptico del control y la separación: ¿cómo responden estas parejas? Tal vez con un discurso suplementario, similar pero invertido que reinventa sin cesar el mito corporativo, pone en palabras el cuerpo de la manada visto desde su interior, enfatiza los lazos amorosos que los/ las hermanan en la vida misma.

Ante tanto estigma y control, poder político y discurso etológico, la minoría (o la manada, en sentido psicológico, obviamente) se apoya en la mitología de las formas casi biológicas o zoológicas de la ternura. Vive la angustia y el desamparo

\footnotetext{
${ }^{4}$ Etología: Estudio científico del carácter y modos de comportamiento del hombre. Parte de la biología que estudia el comportamiento de los animales (Diccionario de la Real Academia Española, s/f. Disponible en: http:// diccionario.terra.com.pe/cgi-bin/b.pl)
} 


\section{hevista all pautg}

\} DIFERENCIAS Y IDENTIDADES SEXUALES: LECTURAS CRÍTICAS - BERMÚDEZ, M. S. M. \}

del individuo, la discriminación. Siente el alivio de agruparse, de reunirse con pares y semejantes, de hacer manada: he encontrado a mi verdadera familia, reconstruyo las relaciones de parentesco y consanguinidad, pertenezco a una minoría que me acepta y me quiere y formo una familia muy similar a mí. El gran grupo hegemónico no marcado, justamente todo lo que no es familia o manada, lo diferente a mí, me rechaza. La contrapartida de este nuevo desamparo: la comunión de la manada, la familia conformada respetando, en última instancia, las marcas. He aquí la identidad, el orgullo y una forma defensiva de las minorías, por otra parte, políticamente comprensible.

A la manada la une un lazo, una cohesión más fuerte que el pacto familiar. Metafóricamente, el lazo es empático, magia, objeto milagroso, orgullo alrededor de un objeto. Más verdadera que la familia de origen, la manada no es una condena genética o un mero accidente sanguíneo: es alianza, el nuevo cuerpo que elijo y que me elige, después de que el viejo cuerpo me ha rechazado. La manada no se obtiene por generación como la familia, sino por elección e identificación profunda, por una suerte de no diferenciación: soy igual a quien elijo. Y en esta tensión dialéctica se dibuja el sueño de los arreglos afectivos - sexuales homosexuales, síntesis entre familia y manada, comunidad y sociedad, elección y corporativismo, identidad e indiferenciación.

Si la comunidad decanta en el camino que recorre del estigma al pedigre, como dijimos, en esta primera instancia ese pedigre no es solamente orgullo e identidad, sino una respuesta vital y desmesurada ante la discriminación y formas de control social sobre los diferentes. Pero avancemos un poco más.

El discurso etológico del poder panóptico había concebido al otro como cosa, lo diferente, lo desviado. Pero el otro, en este caso, una pareja homosexual, lo toma, lo pliega y lo imbrica en mitos correctivos para crear un discurso suplementario, invertido, un imposible discurso de manada, a través del cual, el otro obtiene un esquema de sí mismo, se organiza y defiende. Es esta reterritorialización del discurso etológico del poder panóptico el que construye a la minoría, al poner un plus donde había un estigma, crea la comunión, la noción de orgullo o de pedigree. Pero la minoría no es, con respecto al poder panóptico otra cosa, no está fuera de aquel. Es un discurso reactivo, cautivo de ese universo, destinado a verificar su lógica. Igual es claro que la manada es respuesta a la deshumanización de la que es objeto por parte del poder policíaco.

La minoría es algo defensivo: la organización de un contrapoder tan policíaco como aquel otro que la aisló y la guetizó. La minoría así planteada, no posee una crítica filosófica al universalismo de la carencia, ni una resistencia de gueto ante una cultura falocéntrica. El falo continúa existiendo tanto en el pene de donde proviene el semen como en los espéculos y material ginecológico utilizado para controlar el embarazo de una mujer lesbiana que se inseminó o en el cuerpo femenino alquilado por una pareja gay. Creemos que hay una conducta organizacional defensiva con respecto a poderes policíacos, profundamente normativos e internalizados. Y no son aleatorios. Poseen raíces en la propia historia del modo de producción dominante y especialmente en el país que podríamos decir es su máximo exponente: Estados Unidos. 


\section{Minorías y teoría política: líneas de indagación invisibles para el Trabajo Social políticamente correcto}

Para las culturas de gobierno, la consigna de conocerme a mí mismo equivale a teorizarme o interpretarme, y tiene como objetivo la utopía cívica de liberarme y construir mi soberanía. Para las culturas protestantes y pragmáticas, que atraviesan la cultura estadounidense, conocerme quiere decir más bien tener esquemas de reconocimiento con mis semejantes y hacer manada, con el objetivo de defenderme. Este sea tal vez el verdadero sentido de las nociones de identidad y de cultura en el discurso de la minoría.

La comunidad protestante se especializa en segregar minorías culturales. La sociedad del mercado, del capital y del consumo se diversifica: revistas para negros, supermercados gay, turismo amigable para el movimiento gay, videoclubes para lesbianas. Las minorías parecen condenadas a reproducir la lógica del orden social. La minoría establecerá, especialmente aquellas relacionadas con opciones sexuales, una estrategia típicamente reformista de lucha por el reconocimiento cultural y jurídico, reformas o enmiendas a las reglas y a las normas. Comunidad - minoría más comunidad, es la dinámica política de la sociedad protestante americana.

Parecería que existe un componente ritualizado de los movimientos políticos de las minorías: sus formas convencionales de hacer política, sus protocolos. La gran ilusión política de la tolerancia, la diversidad y una democracia omnímoda, de una política sin economía política (ZIZEK, 2001). Siendo conscientes que estas notas pueden ser mal interpretadas, las minorías a las que hacemos referencia, tal vez no sean una exacerbación de multiculturalismos sino su objeto más representativo.

\section{La izquierda y lo meramente político}

En lustitia Interrupta (1997), Nancy Fraser sostiene que movimientos como el feminismo, el antirracismo, plantean desafíos que ninguna izquierda debería ignorar. Agrega que algunos de estos movimientos, por ejemplo los vinculados a raza y etnia, están enraizados en la economía política, mientras que otros, como los movimientos de lesbianas y gay, no. Su fundamentación es la siguiente: al no constituir una clase explotada, la injusticia que estas minorías sufren se debe esencialmente a una cuestión de aceptación; por tanto, sus luchas serían más asunto de reconocimiento cultural, que de liberación de una opresión material.

A su colega y coterránea Judith Butler (2000) la postura de Fraser le resulta peligrosa: no se puede dividir los movimientos minoritarios en grupos de primera y segunda, según puedan o no justificar su existencia en una dimensión económicopolítica o en otra "meramente cultural". Argumenta en primer lugar, la impertinencia de la propia división entre ámbito material y cultural, y en segundo término, que género y sexualidad forman parte de la vida material. Apela a autores de la izquierda europea, desde Marx a Althuser e incluso Foucault, para persuadir al lector - y a Fraser - que todo en última instancia - sexualidad, género, identidades - termina por tener raíces en la economía política.

¿Es necesario aclarar que siempre es posible anudar la economía política y la economía libidinal? Gramsci (1981, p.194) ha dado una respuesta: 


\section{hevistg all pautg}

\} DIFERENCIAS Y IDENTIDADES SEXUALES: LECTURAS CRÍTICAS - BERMÚDEZ, M. S. M. \}

El industrialismo es una continua victoria sobre la animalidad del hombre, un proceso ininterrumpido y doloroso de sojuzgamiento de los instintos a nuevas y rígidas costumbres de orden, exactitud y precisión (...) El trabajo, por ejemplo, exige una rígida disciplina de los instintos sexuales, un fortalecimiento de la familia en sentido amplio (no de esta o aquella forma histórica), de la reglamentación y estabilidad de las relaciones sexuales.

En otro sentido también Foucault (1977a), ha derribado la hipótesis represiva, sostenida por el marxismo, diríamos clásico. En este artículo no incursionaremos en esta discusión. No creemos que las luchas reales de las minorías sexuales tengan un sentido económico-político, aunque en última instancia, puedan ser remitidas analíticamente al ámbito de la economía política. Esta última aseveración, se comprenderá, no es en absoluto lo mismo.

Insistimos en la idea de que la Comunidad segrega minorías que, amparadas en un simulacro de liberación, reduplican a la comunidad, lo que no significa que dejemos de reconocer sus luchas reales, sus víctimas, sus damnificados, sus muertos, sus conquistas. Queremos contraponer el argumento de Butler sobre la inestable, ambigua e inapropiada distinción entre economía y cultura y que género y sexualidad son nociones o categorías básicamente económico-políticas, con el argumento contundente de Spivak (1985, p.233):

(...) Si el insurgente campesino fue la víctima y el héroe desconocido de la primera ola de resistencia contra el imperialismo territorial en la India, se sabe muy bien que, por razones de connivencia entre las estructuras patriarcales preexistentes y el capitalismo internacional, la mujer subproletaria urbana es el sujeto paradigmático de la configuración actual de la División Internacional del Trabajo. Conforme investigamos las pautas de resistencia entre estas 'eventuales permanentes', los problemas de constitución-de-sujetos en la mujer subalterna van adquiriendo importancia.

Comparemos esta cita con otra de Butler (2000, p. 115-116):

¿Es posible distinguir, aún analíticamente, entre la falta de reconocimiento cultural y la opresión material cuando la misma definición de 'persona' legal está rigurosamente constreñida por las normas culturales que son indisociables de sus efectos materiales? Por ejemplo, en los casos en los que se excluye a lesbianas y gays de las nociones de familia definidas por el Estado (que de acuerdo con el derecho tributario y de propiedad, es una unidad económica); cuando se les excluye, negándoseles la condición de ciudadanía; cuando se ven privados de forma selectiva del derecho a la libertad de expresión y reunión; cuando 
se les priva del derecho a expresar su deseo (en tanto miembros del ejército); o no se les permite legalmente tomar decisiones médicas de urgencia sobre el amante moribundo, heredar las propiedades del amante muerto o recibir del hospital el cuerpo del amante fallecido: ¿no indican estos ejemplos cómo la 'sagrada familia' constriñe, una vez más, los mecanismos que regulan y distribuyen los intereses relativos a la propiedad?

Queremos destacar tres puntos. Primero: la reproducción de lo mismo comunitario se expresa en la cita en el argumento contrario: con el pretexto de luchar contra una estructura jurídica recalcitrante y reaccionaria, la minoría no puede sino establecerse como una prolongación de esa estructura, aunque sea bajo la modalidad de personas de segunda, que esperan calificar para ser personas de primera. En segundo lugar, en esta cita, el capitalismo, eso no dicho y el supuesto incuestionado, hace parte de la nueva izquierda multiculturalista (ZIZEK, 2001). Parecería que todo termina bien cuando el/la homosexual hereda la propiedad de la pareja muerto/ a, o cuando logra ser reconocido/a como persona jurídica, o puede expresar su opinión u opción en el ejército y así sucesivamente. Parecería que no se trata de una rebelión contra la Sagrada Familia, sino un intento por ser aceptado por ella. Siguiendo esta línea de pensamiento, parecería que las minorías sexuales existen en lo meramente político - lo jurídico - litigante - reformista - o en palabras de Fraser (1997), es un tema de aceptación o reconocimiento. Por último, es sorprendente que la rigidez del puritanismo familiar y su base económica guíe las protestas multiculturalistas cuando en realidad el capitalismo mundializado, especialmente en EE.UU, se apoya en la libre circulación de voces y deseos en el mercado. Basta un ejemplo: el amplio abanico y la riquísima ontología de las perversiones para la industria del sexo.

\section{Proceso de cierre y nuevos cortes}

No hay ontología ni cosmogonía que no sea hipótesis de trabajo, tanto teórico como ético. Esto es lo que intentamos realizar. Quizás uno de los mayores peligros al analizar esta temática sea terminar por obturar la problemática clásica de la infraestructura, de la base económica de la sociedad. Todo aquello que despuntaba como una protesta contra el autoritarismo estatal y burocrático, también contra la estructura y dinámica de la izquierda clásica, aquello que parecía una faena de debilitamiento de su ontología inherente, una vez caído el mundo socialista y en plena mundialización del capital especulativo, deviene en una celebración exacerbada de la democracia por la democracia. Eso que podríamos Ilamar izquierda protestante, el compromiso con los multiculturalismos en las culturas comunitarias del Primer Mundo, es su mayor evidencia. Quizás toda tolerancia política supone su gran no dicho: la intolerancia y robustez del capital. O como señala Brown (1995, p.60): "(...) la influencia política de la política de identidad estadounidense parece lograrse, en parte, a través de cierta renaturalización del capitalismo".

Más allá del debate sobre los derechos de las minorías sexuales y sus derechos a legitimar sus uniones o a reproducirse, vale la pena reiterar que su discurso sólo puede enraizarse en ese capitalismo renaturalizado. 


\section{hevista all pautg}

\} DIFERENCIAS Y IDENTIDADES SEXUALES: LECTURAS CRÍTICAS - BERMÚDEZ, M. S. M. \}

La cultura capitalista es rigurosamente contemporánea, pero creemos que es perfectamente posible reconstruir, formalmente, su linaje, a modo de trazo histórico que desemboca en ella. Las formas históricas de organización comunitaria -por ejemplo, las comunidades protestantes - son un claro antecedente de estas formas brutalmente asimbólicas o "no edípicas" del capitalismo contemporáneo. Como ya lo ha dicho Weber (1969:37) son su condición de posibilidad y citando a Gothein indica que son "un vivero de la economía capitalista".

No podría entenderse totalmente la historia de las minorías sexuales sin comprender las diferencias entre culturas institucionalistas y comunitarias, distinción que es pertinente a la luz de la historia contemporánea. Ambas definen dos formas bastante diferentes de regular y cohesionar a las personas y, por lo tanto, dos prácticas opuestas de producción, circulación y apropiación de discursos, saberes, sujetos y experiencias colectivas. Es pertinente y necesario distinguir conceptualmente entre estas dos formas de agrupamientos de las personas y dos técnicas de regulación de las poblaciones: instituciones y comunidades (WEBER, 2003).

La institución está estructurada por la terceridad del Estado. Las personas se reconocen sólo porque antes reconocen a la institución que las contiene y las sostienen: se reconocen sobre el suelo de la institución y por la garantía de la institución. Son capaces de verse solo a través de la mediación y modelización de un tercero: el Otro, el Estado. Esa estructura, organización triangular, es reproducida por el funcionamiento de cualquier interpelación corriente: ciudadanos, correligionarios, camaradas, colegas, etc. La institución es propia de culturas de sujeción (ALTHUSSER, 1977, p. 1988).

La comunidad es totalmente distinta: horizontal, indiferenciada. Se diría que se levanta, en su aparente laxitud, como una fortaleza, precisamente para minimizar los riesgos de una intromisión del Estado, para conjurar el peligro de cualquier riesgo simbólico. El mundo es adentro/afuera, funciona de acuerdo a la subsecuente lógica defensiva, militar o policíaca. Un adentro pegoteado e inestructurado que trata de articularse en forma ritual y un afuera hostil hecho a golpes de exclusión y discriminación. La comunidad es propia de culturas de identidad o identificación.

Aunque funcione más con relación a la autorización que a la autoridad, la institución responde siempre a un modelo vertical y autoritario. Todo en ella remite, envía, transfiere, representa. Es una máquina de producir sentido, todo se interpreta como en la "Psicopatología de la Vida Cotidiana" (FREUD, 1999)

La comunidad en cambio, es una máquina simple, pragmática, incesantemente funciona: clasifica, cuenta, controla, censa. Es una sociedad de identificación y no de subjetivación. Rechaza, no reprime. Más que sentido, la comunidad produce secuencias de orden. Si la institución es propiamente un aparato del Estado, de acuerdo a Althusser, la comunidad es antiestatal. Si la institución genera individuos/ sujetos (ALTHUSSER, 1977), la comunidad produce grupos, manadas, guetos, familias, minorías, hermandades. Si la primera genera subjetividades, la segunda identidades (FREUD, 1999).

Esos trazos que se marcan en suelos movedizos, pues no es la simple asociación entre catolicismo/institución, protestantismo/comunidad, aunque algo de ello hay, reiteramos, hacen a la historia del capitalismo, contexto en el que deben ser interpretadas estas reflexiones. 


\section{AnVistg all pgutg}

\} DIFERENCIAS Y IDENTIDADES SEXUALES: LECTURAS CRÍTICAS - BERMÚDEZ, M. S. M. \}

Pero estas líneas también deben ser contextualizadas en otros términos. La ética es más una reflexión filosófica que una ciencia social y/o humana y como tal no es incorporable al dinamismo de una mirada científica integral, pero sí hay un uso ético de los productos de las ciencias. La temática abordada nos coloca en un lugar en el cuál Trabajo Social debería conciliar y hacer compatible el rigor científico con el compromiso político con la verdad y con la denuncia de las injusticias que impone el orden social vigente, tanto a nivel material y subjetivo como simbólico (TÉLLEZ y VELASCO, 2004). 


\section{hevista all pautg}

\} DIFERENCIAS Y IDENTIDADES SEXUALES: LECTURAS CRÍTICAS - BERMÚDEZ, M. S. M. \}

\section{Referências bibliográficas}

ALTHUSSER, L. Posiciones. Barcelona: Anagrama, 1977.

BROWN, W. States of injury. Princeton: PUP, 1995.

BUTLER, J. El marxismo y lo meramente cultural. New Left Review. London: n. 2, p.109-121, may-jun, 2000.

DICCIONARIO DE LA REAL ACADEMIA ESPAÑOLA. S/f. Disponible en: http:// diccionario.terra.com.pe/cgi-bin/b.pl. Acceso el 18 de jun. 2011.

DONZELOT, J. A policía das famílias. Rio de Janeiro: Graal, 1986.

FOUCAULT, M. Historia de la sexualidad I: la voluntad de saber. México: Siglo XXI, 1977a.

. Vigiar e punir: nascimento da prisão. Petrópolis: Ed. Vozes, 1977b.

. Hermenéutica del sujeto. Buenos Aires: Altamira, 2001.

FRASER, N. lustitia interrupta: reflexiones críticas desde la posición postsocialista. Colombia: Siglo del Hombre Editores, Universidad de los Andes, 1997.

FREUD, S. Psicopatología de la vida cotidiana. Barcelona: Alianza, 1999.

GOFFMAN, E. Estigmas. Buenos Aires: Amorrortu, 1999.

GRAMSCI, A. Cuadernos de la cárcel. Tomo I. Méjico: Ediciones Era, 1981.

SPIVAK, G. Estudios de la subalternidad: reconstruyendo la historiografía. In: GUHA, R. (ed). Subaltern studies IV: writings an South Asian history and society. Delhi: Oxford University Press, 1985, p. 197-245.

VELASCO, H. Prólogo. In: Téllez, A. (coord) Experiencias etnográficas. San Vicente: España: Club Universitario, 2004, p. 3-8.

WEBER, M. La ética protestante y el espíritu del capitalismo. Barcelona, Península.1969.

ZIZEK, S. El espinoso sujeto: el centro ausente de la ontología política. Buenos Aires: Paidós, 2001.

Recebido em 29 de agosto de 2011

Aceito para publicação em 15 de dezembro de 2011 